\title{
Management of Separated Instruments from the root canal- A Review
}

\author{
Dr Aji Markose \\ Dept of Conservative Dentistry, Vivekanda Dental College for Women, Tiruchengode, Namakkal (Dist), \\ Tamilnadu
}

\begin{abstract}
The fracture of an instrument is a recognized complication in endodontics.Several factors must, however be taken into account to evaluate the prognosis of the tooth in this situation. The objective of the endodontic treatment with (or) without a fractured instrument remains the same, namely to disinfect the root canal and prevent its recontamination. The time at which file fracture occurred during treatment and the degree of canal infection must be considered when determining the potential effect on treatment outcome. Patient should be informed about an instrument fracturing in the tooth for ethical and legal reasons.
\end{abstract}

\section{Introduction}

In routine endodontics a clinician may encounter with many procedural errors and obstacles which may alter the course of treatment at any stage (1). One of the procedural errors is the fracture of instrument inside the root canals. Many clinicians associate "broken instruments" with separated files, but the term could also apply to a sectioned silver point, a segment of lentulo, a gates glidden drill, lateral or finger spreaders, and paste fillers and they can be made from nickel-titanium,stainless steel or carbon steel (2). With the advent of rotary NiTi files, there has been an unfortunate increase in the occurrence of broken instruments(3).Today separated instruments can usually be removed due to technological advancements, ultrasonic instrumentation, and microtube delivery methods(4-5).Specifically, the dental operating microscope allows clinicians to visualize most broken instruments(6).The ability to non-surgically access and remove a broken instrument will be influenced by the diameter,length and position of the obstruction within a canal and the type of the metallic $\operatorname{object}(2,7)$

Instruments located in the straight portion of the canal can usually be removed(8). If the entire segment of the broken instrument is apical to the curvature and safe access with visualization is not possible,then nonsurgical removal usually cannot be accomplished(8).Leaving a fractured instrument inside the root canal coupled with incomplete obturation or ineffective coronal seal may lead micro-organisms to penetrate inside the canal and develops periapical lesion.Oztan and Soares et al. have confirmed that large periapical lesions can respond favorably to nonsurgical treatment using calcium hydroxide paste $(9,10)$.

\section{Several factors predispose to instrument separation (11)}

1) Anatomic complexities (eg. severely curved canals)

2) Instrumentation technique (those that involve counter-clockwise rotation like the balanced force technique.

3) File design ( Certain files like $\mathrm{H}$ files are more prone to fracture)

4) Manufacturing defects- sometimes defects like cracks, metal flash,roll overs etc can predispose to file fracture.

5) Instruments can also separate due to either abuse or overuse.

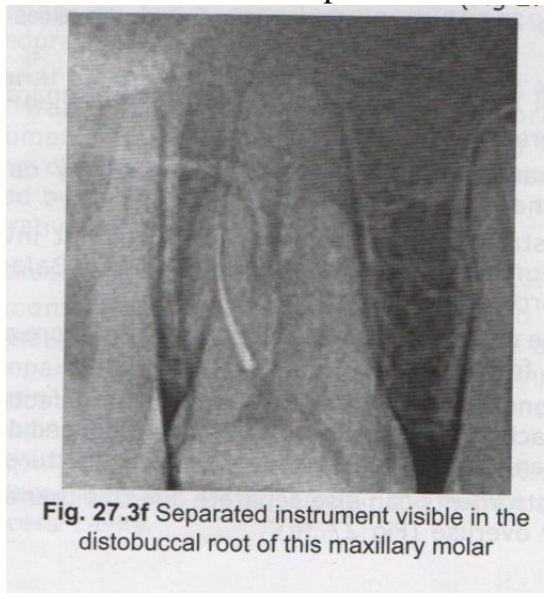

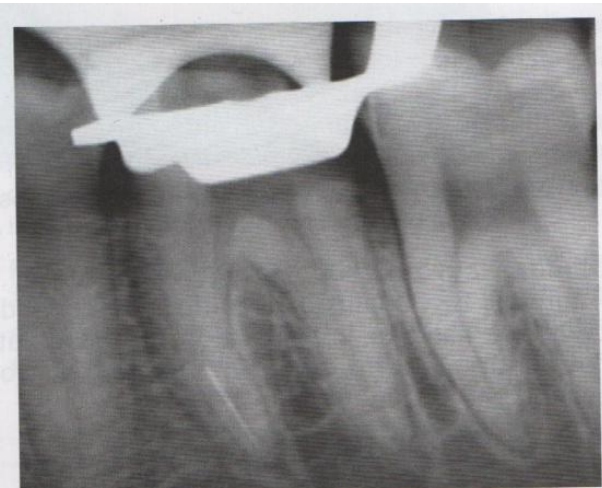

Fig. 27.3o Separated instrument visible in the mesial root of this mandibular molar 


\section{What are the treatment options $(12)$}

When an instrument fractures in the root canal system a decision has to be made to leave,bypass or remove the fragment, the choice being based on an assessment of the potential benefit of removal compared with the risk of complication. The interests of the patient are paramount in this decision as they may opt to have the tooth extracted for reasons such as anxiety, time and finance.

\section{Leave Fractured Instrument In Situ}

Historically, it was recommended that regardless of the preoperative status of the pulp,the fractured instrument should be left in situ and root canal treatment completed coronal to the fragment, before a period of review $(13,14)$ It was proposed that the fractured instrument generally did not affect prognosis and therefore could be retained, as the risk of removal was high. Although it was suggested that the retention of the fractured instrument did not affect prognosis, it is logical to assume that the fragment will compromise chemo-mechanical cleansing, working length control and root canal filling(15). From the patients perspective, retaining the fractured instrument can be a source of anxiety as it can be viewed as a treatment failure or even clinical negligence and may be perceived as the source of any problem the patient may encounter in the future.

\section{Remove Fractured Instrument}

Recently, it has been suggested that removal should always be attempted(16), the fragment only being retained when nonsurgical removal has been unsuccessful(17). The rationale is (as previously stated) that unless the obstruction in the canal is removed- allowing complete chemo-mechanical disinfection of the root canal system - outcome will be significantly reduced $(15,18)$. Furthermore, it has been reported that in the presence of a periapical lesion, endodontic treatment which is complicated by procedural errors - such as fractured instrument- demonstrated reduced healing $(15,19)$. Obviously, removal should improve working length controlassuming there is minimal canal aberration- and facilitate effective obturation of the root canal system(20). Successful removal of the fragment from the tooth also provides psychological benefits for the patient and avoids the risk of medico-legal action. Where conditions are favourable, removal of the retained fragment can be a conservative procedure(21), But in cases where access to the fragment is difficult and/or visibility limited, removal may lead to iatrogenic errors such as ledge formation, perforation or excessive enlargement of the canal; this results in a weakened tooth structure which predisposes to vertical fracture $(20,22)$. Additional complications of removal involve fracture of a second instrument or extrusion of the fractured segment. If nonsurgical removal is not possible, surgical removal of the portion of the root containing the fractured segment has also been advocated, however this procedure relies on considerable surgical skill and may also reduce the crown-root ratio(23).

\section{Bypass Fractured Instrument}

Other authors suggest that it is more conservative to bypass the fractured instrument, particularly in cases where access to the fragment is restricted (apical one-third of canal or beyond the canal curvature) and its removal may lead to excessive removal of dentine with associated sequelae(24,25). Interestingly, it has been reported that if the file is bypassed, the retained fragment does not compromise obturation quality(26).

\section{What other factors influence clinical decision making Periodontal and restorative status of tooth}

Periodontally compromised teeth do not make good candidates for instrument removal, although it can be considered if the periodontal condition is stable and they are informed of the risks of removal. In cases where teeth are unrestorable subsequent to instrument removal, extraction should be considered, as there is no virtue of spending further resources (patient or dentist) treating a tooth with hopeless prognosis.

\section{Patient factors}

Fractured instrument removal generally involves a prolonged period in the dental chair, therefore, general dental issues such as patient apprehension and time constraints become more pertinent. Health issues may also alter the balance in favour of instrument removal if extraction is best avoided.Conditions such as severe bleeding disorders or patients receiving intra venous biphosphonate medication are at increased risk of postoperative complications subsequent to dental extractions(26). Finally, cost to the patient may be an influencing factor as removal of fractured files is a technically challenging procedure,often the requiring the assistance of a specialist. Patient may decide that removal of the fragment is not worth the additional financial outlay compared to extraction or observation. 


\section{How successful are clinicians at removing instruments And what influences that success?}

The factors that help in the removal of a fractured instrument can be broadly grouped as (1) the location, length and type of fractured instrument (2), the tooth/canal involved, and (3) the clinicians skill and valuable armamentarium.

Location-With the introduction of the operating microscope into clinical dentistry, instruments in the straight portion of the canal can be generally removed, while fractured instruments that lie partially in the canal curvature- although more challenging - can also be removed(21).The bulk of the literature- both in vitro and in vivo studies- agrees that when fragments are localized apical to the canal curvature, removal is compromised, often impossible and generally ill advised(17,20). Nonetheless, the authors also reported the potential for perforation was greater when removal was attempted in the apical third of the root canal (27).

Length- Hulsmann and Schinkel(17) proposed that longer fragments would be easier to remove than short fragments, explaining that fragments $(>5 \mathrm{~mm})$ were likely to engage dentin at their tips, creating space coronally to allow loosening of the fragment, however this notion was not demonstrated experimentally.

Type- It was previously demonstrated that fractured instrument type had a significant influence on success of removal, with removal of reamers and lentulo spirals provide more successful than Hedstrom files(17).

Material- Stainless steel (SS) files are considered to be easier to remove than nickel-titanium (NiTi) instruments, which have a higher propensity to fracture further during the removal process, perhaps due to accumulation of heat from direct ultrasonic vibration(21). Other suggested explanations for the increased difficulty of removing rotary $\mathrm{NiTi}$ instruments include the fact that they effectively engage or lock into the canal during rotation and tend to fragment into smaller pieces often at or around the curves of narrow canals. $(20,27)$

\section{Tooth/canal involved}

Root anatomy such as the diameter, length,canal curvature and thickness of the root dentine has been reported to affect the potential to safely remove a fractured instrument(28). There is general agreement that curved canals (particularly buccal canals of maxillary molars and mesial canals of mandibular molars) present a significantly higher risk of instrument fracture than straight canals $(17,27)$.

\section{Clinicians Skill and available armamentarium}

The clinicians experience, competence and attitudes regarding the impact of a fractured file on prognosis are important factors in the management of a fractured instrument(21). Removal of fractured files is technically demanding and is largely within the remit of an endodontic specialist.Selecting and effectively using the appropriate equipment from the plethora of innovative new technologies and operating them efficiently require experience and judgement.Several authors have noted the importance of operator skill and experience on successful removal as well as the negative effect of operator fatigue $(17,20)$. Interestingly, with regard to clinical time spent removing the fragment,studies demonstrate a lower success rate and an increased prevalence of complications when operator time exceeded 40-60 mts(20,27). In modern endodontic practice fractured instruments can be removed more predictably, which has been credited to technological advances including the use of dental operating microscope, ultrasonics and microtube extraction devices.
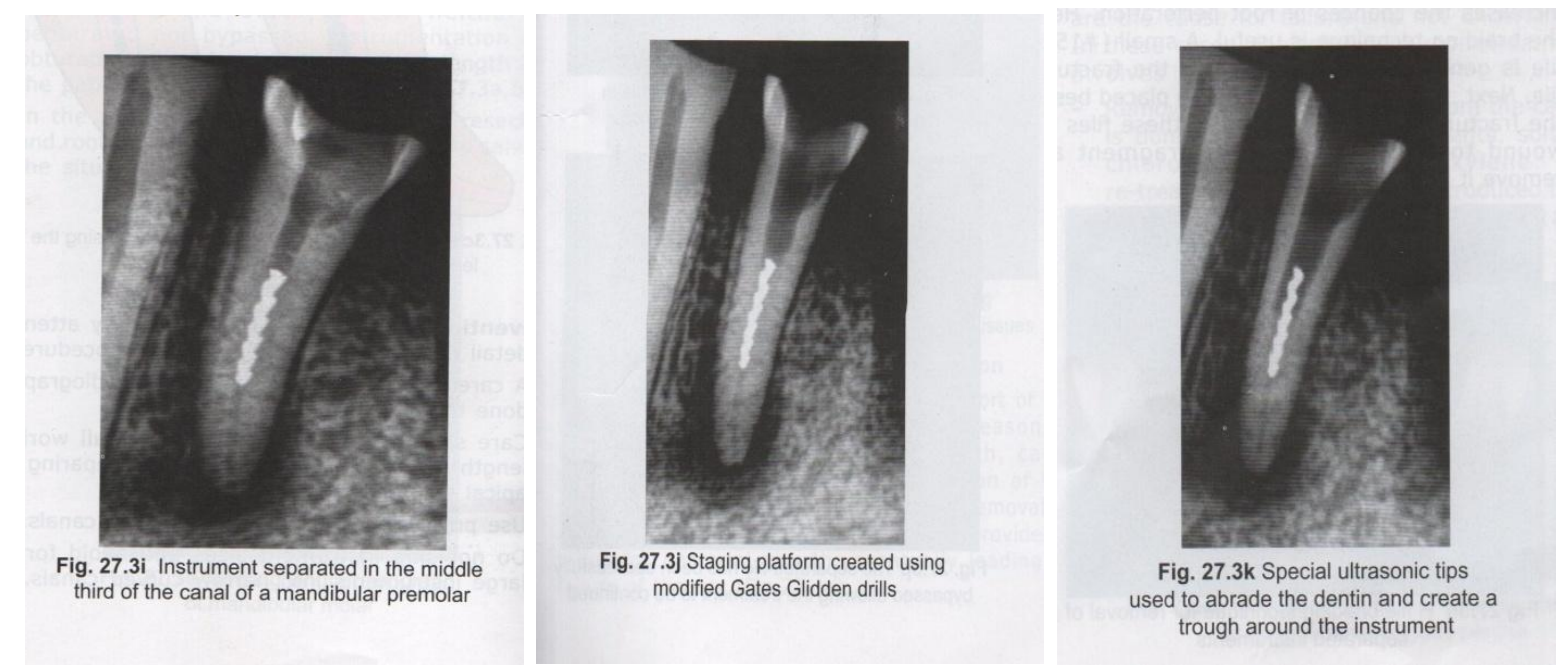


\section{Methods of Removal}

If the clinician elects to remove the fractured segment,a wide array of techniques and devices has been developed to facilitate the process. These devices can be broadly categorized as ultrasonics, microtube devices and pliers/forceps.All of the techniques share similar problems of excessive dentine removal,weakening of the root structure,predisposing to ledging,perforation or root fracture and possible extrusion of the fragment through the apex.(21,22,23)Furthermore, since successful removal requires visualization and straight line access to the coronal aspect of the fractured instrument, these techniques are generally used in single rooted teeth or straight roots and have limited application in narrow and curved segments of the root where there is reduced dentine thickness.

\section{Ultrasonic devices}

Ultrasonics in conjunction with a microscope, are considered the most conservative method of removal and as a result have become the most universally and investigated technique, both in vitro and in vivo $(17,20,22)$ The most commonly described technique involves the creation of a staging platform (Classically created by a modified Gates-Glidden drill), which creates sufficient space to allow the specialized ultrasonic tips to trephine around the coronal aspect of the fragment and in so doing agitating, loosening and unwinding of the fractured instrument.Piezoelectric (rather than magnetostrictive) ultrasonic devices are recommended so that a dry field can be maintained to ensure optimal vision, however frequent irrigation is essential to dissipate heat, remove debris and promote chemomechanical cleaning of the root canal system(29).

\section{Microtube extraction}

Microtube extraction generally involves positioning the end of a narrow metal tube over the exposed coronal tip of the fractured instrument, a circumferential trough around the head of the fragment having previously been created by specialised trephine drills supplied by the system

Masserann kit, Cancellier kit,Endo Extractor, Meitrac systems, I R S (Instrument removal system) The tube then engages the fragment mechanically or retains with the aid of a cyanoacrylate glue. The application of such devices is in the main,limited to the straight or coronal section of the canal,with these systems generally being criticized for requiring excessive canal enlargement.

\section{Forceps/pliers}

Stieglitz forceps or plier -type forceps instruments are suitable only in cases where the fragment extents into the pulp chamber and the instrument can engage and grab the coronal aspect of the instrument.(17)However if the instrument is within the root canal, it is generally impossible for the pliers to grab the instrument satisfactorily, without destroying any remaining residual coronal tissue in the process.

\section{Other methods}

Other reported methods for instrument removal include the simple use of chelating agents such as EDTA in combination with stainless steel hand files(21) or the use of a hypodermic needle to manually trephine around the coronal aspect of the fragment.(30)These methods however are largely anecdotal, practiced by a small group of clinicians who have refined this skill rather than being a generally recommended technique.Another reported system is the Canal finder system, a reciprocating device that connects to the air motor and can bypass or remove the instrument $(29)$

With regards to developments in the future, laser (pulsed Nd:YAG laser irradiation) has been described as a possible technique for removing/melting the fractured segment while causing minimal removal of surrounding root dentine.However, substantial research is required into the effects of this technique on the adjacent periodontal tissue and to establish adequate safety parameters, before clinical use can be advocated.

\section{Medico-legal Considerations}

Neverthless, the stressful event of fracture becomes more difficult to defend and manage if the patient has not been informed of the potential risk or indeed of the presence of a fractured instrument in their root canal. What is certain is the fact clinicians have a legal obligation to inform the patient- and document it in the patients notes- if an instrument has fractured during treatment. If removal is deemed the most suitable option, again the patient needs to be informed of the associated risks and an appropriate referral made. In the event of retaining the file, radiographic periodic review is necessary to enable early interception should any associated periapical pathology develop.

\section{Conclusion}

*Fractured instruments can be removed by a variety of methods such as fine ultrasonic tips, micro-tubule devices and pliers/haemostatic forceps. 
*Although many of these techniques have been described as successful, they require skilled use of the operating microscope and generally considered within the remit of the endodontic specialist.

* As removal of a fractured file is associated with considerable risk,bypassing the instrument should be considered.

*The removal of files can be expensive in terms of time and equipment and therefore a cost- benefit analysis of the treatment should be considered before selecting a definitive treatment for the patient.

* Patients should be informed if an instrument fractures during treatment or if a fractured file is discovered during a routine radiographic examination. It is essential legally that the treatment details and the information given to the patient are recorded accurately in the patients notes.

\section{References}

[1]. Torabinejad M,Lemon RR, Procedural accidents.In:Walton R, Torabinejad M,eds.Principles and practice of endodontics. Philadelphia: W.B.Saunders Company,2002:310-330

[2]. Parashos P, Messer HH, Rotary NiTi instrument fracture and its consequences. J Endod 2006;32:1031-1043

[3]. Ankrum MT, Hartwell GR, Truitt JE, K3 Endo,ProTaper,and Profile systems:breakage and distortion in severely curved roots of molars.J Endod 2004;30:234-7

[4]. Plotino G, Pameijer CH, Grande NM, Somma F.Ultrasonics in endodontics: A review of the literature.J Endod 2007;33:81-95

[5]. Ruddle CJ.Broken instrument removal.The endodontic challenge.Dent Today 2002;21:70-72,74,76 passim.

[6]. Suter B, Lussi A, Sequeira P.Probability of removing fractured instruments from root canals. J Endod 2005;38:112-123

[7]. Terauchi Y et al.Evaluvation of the efficiency of a new file removal system in comparison with two conventional systems.J Endod 2007;33:585-588

[8]. Roda RS, Gettleman BH. Non surgical retreatment. In:Hargreaves KM, Cohen S,eds. Pathways of the pulp, ed.10 St Louis:Mosby;2011:890-952

[9]. Oztan MD.Endodontic treatment of teeth associated with a large periapical lesion. Int Endod J 2002; 35:73-78

[10]. Soares jA, Brito-Junior M, Silveira FF, Nunes E, Santos SM. Favourable response of an extensive periapical lesion to root canal treatment. J Oral Sci 2008;50:107-111

[11]. Ramya Raghu, Raghu Srinivasan, Text Book of Endodontics, Current Concepts and Practice, First Edition,2015

[12]. M.B McGuigan, C.Louca and H.F.Duncan, Clinical decision- making after endodontic instrument fracture, British Dental Journal,2013;214:395-400

[13]. Crump M C, Natkin E. Relationship of a broken root canal instrument to endodontic case prognosis: a clinical investigation. $J$ Am Dent 1970;80:1341-1347

[14]. Fox J, Moodnik R M, Greenfield E, Atkinson J S. Filling root canals with files: radiographic evaluvation of 304 cases. $N$ Y state Dent J 1972;38:154-157

[15]. Sjogren U, Hagglund B, Sunqvist G,Wing K. Factors affecting the long term results of endodontic treatment.J Endod 1990;16:498504

[16]. Machtou P, Reit C Non surgical retreatment. In Bergenholts G, Horsted-Bindslev P, Reit C (eds) Text book of endodontology, $1^{\text {st }}$ ed, pp 300-310, Oxford:Blackwell Munks Gaard, 2003

[17]. Hulsmann M, Sehinkel I. Influence of several factors on the success or failure of removal of fractured instruments from the root canal . Endod Dent Traumatol, 1999,15:252-258

[18]. Kerekes K, Tronstad L, Long term results of endodontic treatment performed with a standardized technique. J Endod 1979;5:83-90

[19]. de Chevigny C, Dao T T,Basrani B R etal, Treatment outcome in endodontics: the Toronto study - phase 4 J endod 2008;34:258263

[20]. Ward J R, Parashos P, Messer H H. Evaluvation of an ultrasonic technique to remove fractured rotary nickel titanium instruments from root canals: clinical cases. J Endod 2003;29:764-767

[21]. Ruddle C J, Nonsurgical retreatment, J Endod 2004,30:827-845

[22]. Nagai O, Yani N, Kayaba Y, Kodamas S Osada T, Ultrasonic removal of broken instruments in root canals. Int Endod J 1986:19:298-304

[23]. Fors U G H , Berg J O. Endodontic treatment of root canals obstructed by foreign objects. Int Endod J 1986;19:2-10

[24]. Souter N J, Messer H. Complications associated with fractured file removal using an ultrasonic technique. J Endod 2005;31:450452

[25]. Madarati A,Qualtrough A J, Watts DC .A Microcomputed tomography scanning study of root canal space: changes after the ultrasonic removal of fractured files. J Endod 2009;35:125-128

[26]. Saunders J, Eleazer P, Zhang P, Michalek S. Effect of a separated instrument on bacterial penetration of obturated root canals, $J$ Endod, 2004;30:177-179

[27]. Suter B, Lussi A, Sequeira P, Probability of removing fractured instruments from root canals. Int Endo J 2005: 38;112-123

[28]. Rhodes J S, Pittford T R , Linch P J, Liepins p J,Microcomputed tomography: A new tool for experimental endodontology.Int Endod J 1999:32;165-170

[29]. Cheung G S. Instrument fracture:Mechanisms ,removal of fragments, and clinical outcomes, Endod Topics 2009:16:1-26

[30]. Eleazer P D, O’Connor R P, Innovative uses for hypodermic needles in endodontics, J Endod 1999:25:190-191 